\title{
Influence of Al-Si alloy microstructure on the corrosion resistance of coatings formed by the microarc oxidation method
}

\author{
Natalia.Y. Dudareva, ${ }^{1, *}$, Roman.V. Kalschikov ${ }^{1}$, and Liliya.I. Zaynullina ${ }^{1}$ \\ ${ }^{1}$ Ufa State Aviation Technical University, Ufa, Russian Federation
}

\begin{abstract}
The impact of the high-silicon aluminum alloy initial microstructure on the quality of the coating formed by microarc oxidation (MAO) has been studied. The MAO treatment is applied to AK12D samples in the initial coarse-grained state and after high pressure torsion. The following coating properties are studied: thickness, microhardness, porosity and corrosion resistance. It is established that the MAO layers properties depend on the base microstructure much. High pressure torsion applied to AK12D samples before MAO results in increase of the coating thickness by $\sim 2$ times. The microhardness of coatings reduces and their corrosion resistance degrades by $\sim 10$ times.
\end{abstract}

\section{Introduction}

The microarc oxidation (MAO) technique is one of the promising ways to form corrosion resistant coatings [1]. It enables expanding the application area of $\mathrm{Al}$ alloys in commercial production through formation of a modified surface layer of mainly high-strength oxides resistant to aggressive environment [2].

$\mathrm{Al}$ alloys find more application in aircraft and engine building due to their availability and simplicity in processing $[3,4]$. However, parts from $\mathrm{Al}$ alloys should possess not only definite strength properties but also high corrosion resistance for operation under such extreme conditions. Therefore, creation of the corrosion resistant surface on parts from $\mathrm{Al}$ alloys is a topical and complicated task.

The MAO essence is in migrating point microarc discharges taking place on the part surface under high voltage applied between the part in the electrolyte and the electrode [5]. As a result of these discharges the part surface layer transforms in the ceramic layer tightly bonded with the metal base. The quality and properties of the formed coating depend on different factors of the MAO: electrolyte composition, electrical regimes and processing duration [6-8]. The impact of these factors on the MAO layer properties has been studied well. One more important factor effecting the quality of the MAO layer is microstructure of the processed material.

It is known [9] that during the grain size change towards their reduction the volume characteristics of $\mathrm{Al}$ alloys such as strength, microhardness, etc change in a positive way. However, in modern scientific literature there is practically no information on quality and properties of MAO layers on Al alloys with ultrafinegrained (UFG) structure.

Thus, the aim of this work is the study of the initial microstructure effect on the structure and corrosion resistance of the oxide layer formed during MAO.

\section{Experimental}

\subsection{Sample preparation}

Eutectic silumin AK12D OST 192014-90 is chosen for the studies. The chemical composition of the material is 79-84 wt.\% Al,13 wt.\% Si, 1.5 - 3 wt.\% Cu, 0.2 wt.\% Cr, 0.005 wt.\% B, 0.7 wt.\% Fe, 0.8-1.3 wt.\% Mg, 0.3-0.6 wt.\% Mn, 0.8-1.3 wt.\% Ni, 11-, 0.02 wt.\% Sn, 0.05- 0.2 wt.\% Ti, 0.5 wt.\% Zn.

In order to perform the studies on the samples with the base material structure, 3 samples with a diameter of 20 $\mathrm{mm}$ and $2 \mathrm{~mm}$ thick (group 1) are cut from a rod in the asreceived state.

In order to produce samples with UFG structure 3 billets with a diameter of $20 \mathrm{~mm}$ and $2 \mathrm{~mm}$ thick are used. The UFG structure is formed via high pressure torsion (HPT). The HPT technique allows forming a nanostructure with non-equilibrium high-angle grain boundaries in the material during high pressure torsion [9]. The samples are processed by HPT via the following regime: 10 rotations with the velocity $\mathrm{V}=1 \mathrm{rot} / \mathrm{min}$, pressure $\mathrm{P}=6 \mathrm{GPa}$, at a temperature of $20^{\circ} \mathrm{C}$. Prior to HPT the samples are water quenched with preliminary dwelling at $\mathrm{T}=515^{\circ} \mathrm{C}$ for 1 hour. As a result 3 samples with UFG structure with a diameter of $20 \mathrm{~mm}$ and $1 \mathrm{~mm}$ thick are formed (group 2). Prior to the MAO treatment the samples with UFG structure are stored at $-20^{\circ} \mathrm{C}$ to avoid material ageing.

During MAO silicate and alkaline electrolyte on the basis of distilled water is used. The electrolyte composition is $1.5 \mathrm{~g} / \mathrm{KOH}$ and $3.5 \mathrm{~g} / \mathrm{N} \mathrm{Na}_{2} \mathrm{SiO}_{3}$. During the processing the ratio between the cathodic and anodic currents is constant $\mathrm{Ia} / \mathrm{Ik}=1$. The current density is 6.6...6.9 A/ $\mathrm{dm}^{2}$. The electrolyte temperature does not exceed $40{ }^{\circ} \mathrm{C}$. The MAO process is performed till the complete end of sparking on the processed surface, and its duration is 180 minutes.

\footnotetext{
"Corresponding author: natalia jd@mail.ru
} 


\subsection{Microstructure}

The microstructure of the samples is studied with the help of an optical electron microscope "Olympus GX51" at a magnification of $x 500$. The MAO layer studies, thickness measurement, viewing and imaging of pores are performed by a scanning electron microscope (SEM) « JEOLJSM-6490LV» at a magnification of $x 500$.

The volume fraction of pores is determined by point application of the square mesh on the structure image.

The microhardness of the alloy and MAO-layer is determined on a microhardness measuring device StruersDuramin by the Vickers technique. A load of 100 grams is applied for 10 seconds. The microhardness of the coating is determined across the layer thickness.

\subsection{Corrosion Resistance Studies}

In order to test the corrosion resistance, aggressive solution of the following composition is used (chosen on the basis of recommendations listed in GOST 9.904-82):

- sodium chloride $(\mathrm{NaCl})-225 \mathrm{~g} / \mathrm{l}$;

- potassium nitride (KNO3) - $50 \mathrm{~g} / \mathrm{l}$;

- nitrogen acid (HNO3) - $5.5 \mathrm{~g} / \mathrm{l}$;

- base - distilled water.

The total volume of the prepared solution is 3 liters. The edges of the studied samples are covered with special varnish before immersion in the solution. The samples are put in the solution for 6 days (144 hours). After dwelling the samples are taken out of the solution, washed with water, dried and weighed. The corrosion rate is calculated via the formula:

$\mathrm{K}={ }_{\Delta} \mathrm{m} / \mathrm{S} * \mathrm{t}$,

where $\mathrm{K}$ - the corrosion rate, $\left[\mathrm{g} / \mathrm{m}^{2} \mathrm{~h}\right], \Delta \mathrm{m}$ - change of the sample mass, g, S-the surface area $\left(\mathrm{m}^{2}\right)$, $t$-time of dwelling in the solution (h).

The mass of samples is measured with the help of the electronic scales Mettler Toledo XP26 before and after the tests. The measuring accuracy is up to $2.5 \mu \mathrm{g}$.

\section{Results}

The structure analysis of the samples of group 1 (АК12Д in the as-received state) demonstrates that the silicon phase is spread non-uniformly in the material structure. Areas enriched with silicon particles are observed. $\theta$ phase $\left(\mathrm{CuAl}_{2}\right)$ precipitates with the size close to the size of silicon particles are also observed in the structure. The microstructure parameters of the alloy in the initial state are listed in Table 1 (group 1).

The microstructure of HPT-processed samples (group 2) differs considerably from the structure in the initial state (Fig. 1b). The silicon particles are distributed uniformly, the average grain size of the $\mathrm{Al}$ matrix reduces significantly. The microstructure parameters of the UFG alloy are listed in Table 1 (group 2).
Table 1. The microstructure parameters and microhardness of aluminum alloy depending on the group.

\begin{tabular}{|l|c|c|}
\hline \multirow{2}{*}{ Parameters } & \multicolumn{2}{|c|}{ Group } \\
\cline { 2 - 3 } & 1 & 2 \\
\hline $\begin{array}{l}\text { Average grain size of } \\
\text { aluminum matrix }\end{array}$ & $17 \pm 5 \mu \mathrm{m}$ & $200 \pm 15 \mathrm{~nm}$ \\
\hline $\begin{array}{l}\text { Average size of silicon } \\
\text { particles, } \mu \mathrm{m}\end{array}$ & $3,2 \pm 0,7$ & $4,3 \pm 0,7$ \\
\hline $\begin{array}{l}\text { Volume fraction of silicon } \\
\text { particles, \% }\end{array}$ & $23 \pm 4$ & $25 \pm 4$ \\
\hline $\begin{array}{l}\text { Volume fraction of } \theta- \\
\text { phase, } \%\end{array}$ & $3 \pm 1$ & $3 \pm 1$ \\
\hline Microhardness, HV & $92 \pm 4$ & $242 \pm 17$ \\
\hline
\end{tabular}
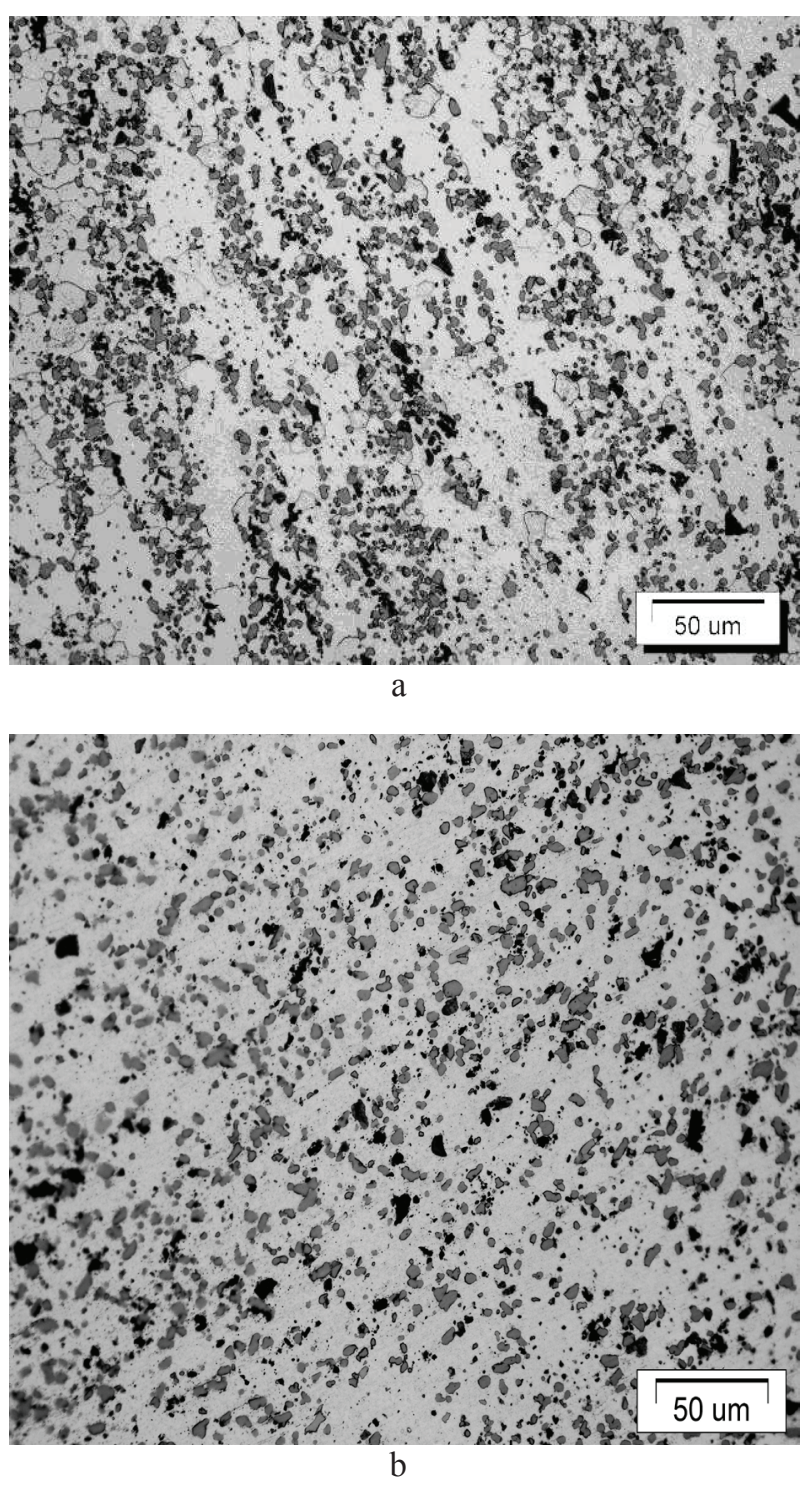

Fig. 1. Optical microstructure of samples: a - group 1; b group 2.

As a result of the studies of the images of cross sections with the MAO layer, it is established that the thickness of the oxide layer is non-uniform in both groups. The average thickness value of the MAO layer on the samples of group 1 is $h=41 \pm 15 \mu \mathrm{m}$ (Fig. 2a), and on the samples of group $2-\mathrm{h}=88 \pm 18 \mu \mathrm{m}$ (Fig. $2 \mathrm{~b}$ ). 


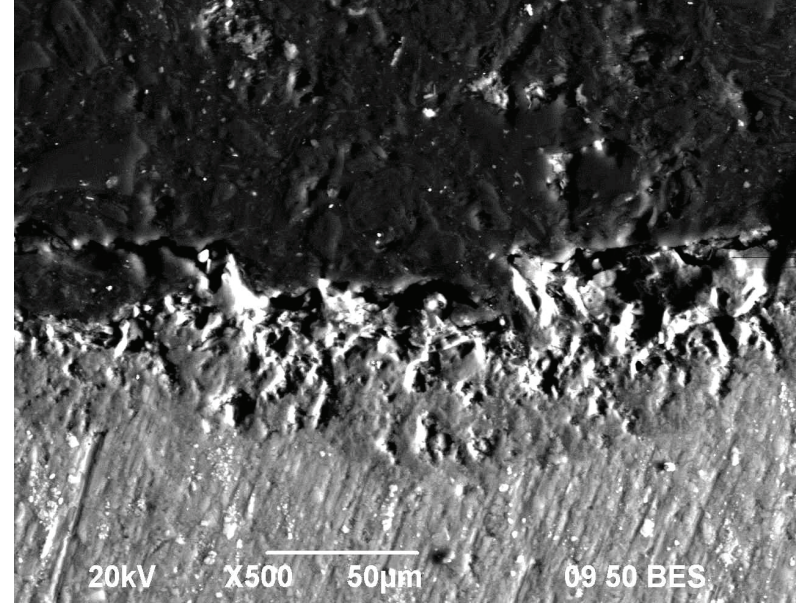

a

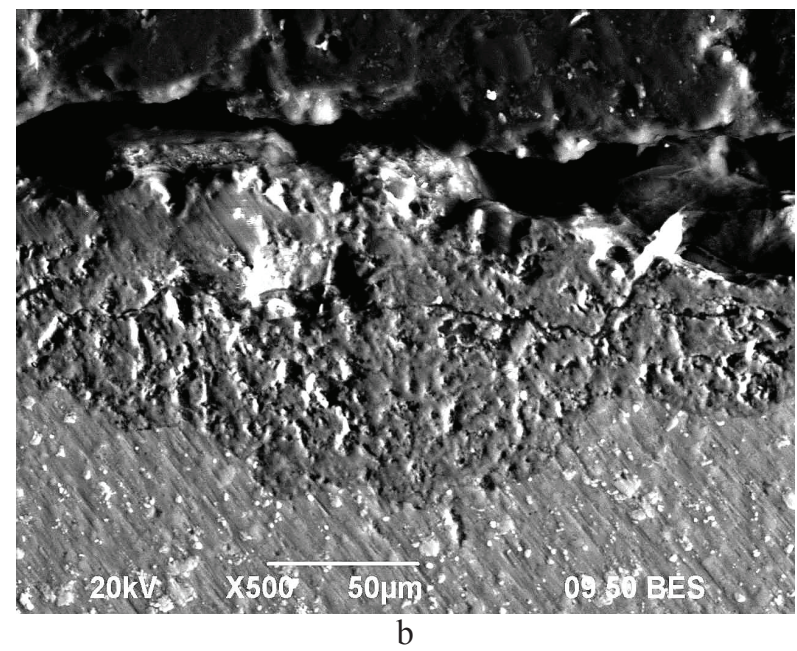

Fig. 2. Alloy AK12D (АК12Д) -coating system : a - group 1; $\mathrm{b}-$ group 2

The results of the porosity study of the MAO layers across the thickness are displayed in Fig. 3. Despite the difference in the distribution of pores and different thickness of oxide layers, the average porosity value of the coating is the same for both groups (Table 2).

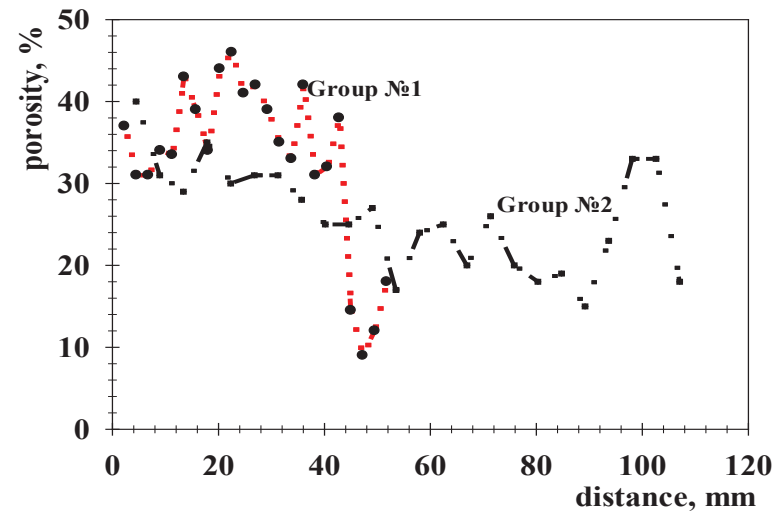

Fig. 3. Distribution of porosity in the MAO layer across the layer thickness on the samples of groups 1 and 2 .

The results of microhardness measurements across the thickness of the MAO-layers are displayed in Fig. 4. The microhardness distribution is non-uniform through the MAO-layer thickness. The maximum value of the coating microhardness is observed in the samples of group 1 and is $900 \mathrm{HV}$. The samples of group 2 have the maximum microhardness value of the MAO-layer of $370 \mathrm{HV}$.

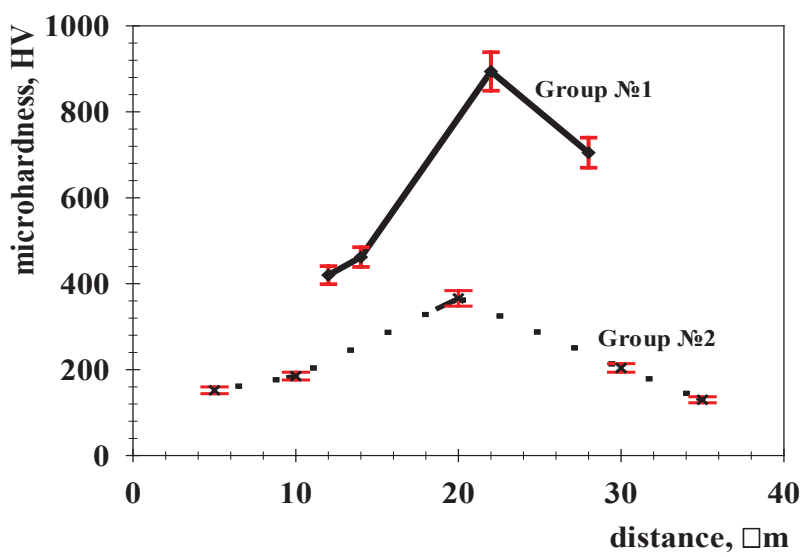

Fig. 4. Microhardness distribution in the MAO-layer across the layer thickness in the samples of groups 1 and 2.

The corrosion test results show that the corrosion rate in the samples of group 2 exceeds that in the samples of group 1 by 10 times (fig. 5a,b).
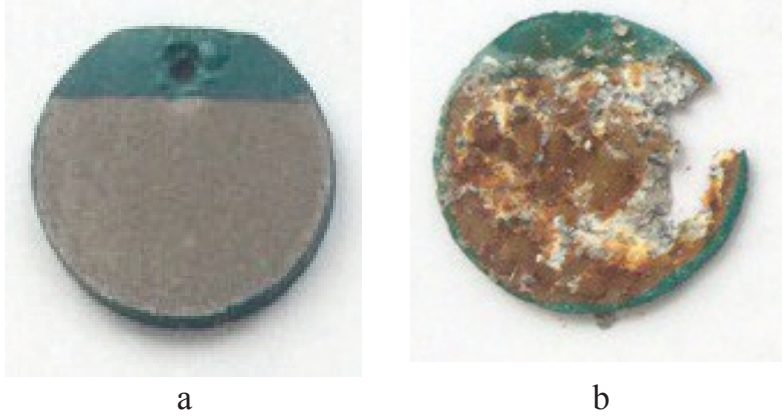

Fig. 5. Samples after corrosion resistance tests: a - sample of group $1, \mathrm{~b}$ - sample of group 2

The summarized results of the studies on the structure and corrosion resistance of the MAO-layers are listed in Table 2.

Table2. Properties of MAO layers.

\begin{tabular}{|c|c|c|}
\hline \multirow{2}{*}{$\begin{array}{c}\text { Properties of the MAO } \\
\text { layer }\end{array}$} & \multicolumn{2}{|c|}{ Group № } \\
\cline { 2 - 3 } & 1 & 2 \\
\hline Thickness, $\mathrm{t}_{\mathrm{av}}, \mu \mathrm{m}$ & $41 \pm 15$ & $88 \pm 18$ \\
\hline The average porisity, \% & $33 \pm 10$ & $30 \pm 6$ \\
\hline $\begin{array}{c}\text { The average } \\
\text { microhardness, } \mathrm{HV}\end{array}$ & $620 \pm 62$ & $207 \pm 23$ \\
\hline $\begin{array}{c}\text { The average corrosion rate, } \\
\mathrm{K}_{\mathrm{av}}, \mathrm{g} /\left(\mathrm{m}^{2} \cdot \mathrm{h}\right)\end{array}$ & $0,229 \pm 0,001$ & $2,678 \pm 0,006$ \\
\hline
\end{tabular}




\section{Discussion}

The results of the performed studies demonstrate strong impact of the initial microstructure of the alloy on the thickness, porosity, microhardness and corrosion resistance of MAO layers.

It is evident that the UFG structure of the material contributes to formation of MAO-layers with higher thickness but lower microhardness. Such a result can be explained by the fact that after HPT the structure of Al alloy is characterized by a small grain size of the Al matrix and developed dislocation structure. Such a structure contributes to deeper penetration of oxygen atoms/ions in the material of the substrate via intercrystallite defects during $\mathrm{MAO}$, which results in increase of the coating thickness [10].

The microhardness reduction in the MAO layers after HPT can be explained by the fact that after HPT silicon particles are uniformly located in the base material of the sample. As a result during MAO interaction of $\mathrm{Al}$ and oxygen becomes difficult. In those parts where silicon comes out on the surface, coating is not formed or its quality is unsatisfactory - no very hard oxides are formed $[11,12]$.

Usually the corrosion resistance directly depends on the coating porosity [13]. However, despite the same average porosity, the MAO layers formed on the samples with UFG structure differ considerably in lower corrosion resistance. By analyzing and comparing the images of polished coatings, one can see that the oxide layers on the UFG samples (Fig. 2b) are characterized by deep cracks passing across the coating. One may assume that these cracks lead to penetration of corrosion-aggressive environment into the sample material and cause active failure of it (Fig. 5b).

\section{Conclusions}

1. The structure of the sample material significantly impacts the thickness, porosity, microhardness and corrosion resistance of the MAO-layer.

2. The reduction of the structural elements sizes in $\mathrm{Al}$ alloy as a result of HPT contributes to decrease of the MAO-layer microhardness ( by 3 times) and leads to increase of the MAO thickness ( $\sim$ by 2 times).

3. The UFG structure of the substrate material contributes to formation of deeper cracks in the coating volume and reduction of the corrosion resistance of the MAO layer by 10 times.

The reported study was partially supported by RFBR, research project №16-38-00827.

\section{References}

1. W. Xue, Applied Surface Science 253, 6118 (2007)

2. H.X. Li, V.S. Rudnev, X.H. Zheng, T.P. Yarovaya, R.G. Song, J. of Alloys and Compounds 462, 99 (2008)
3. R.H.U. Khan, A. Yerokhin, A. Matthews, X. Li, H. Dong, J. Surface and Coatings Technology 205, 1679 (2010)

4. J.R. Davis, ASM International (1999)

5. A.L. Yerokhin, X. Nie, A. Leyland, A. Matthews, S.J. Dowey, J. Surface and Coatings Technology 122, 73 (1999)

6. N.Y. Dudareva, Herald USATU 3, 217 (2013) (in Russian)

7. G.M.M. Elhag, Ph.D. diss (MISA, Moscow, 2007) (in Russian)

8. P.M. Garinov, Ph.D. diss. (MISA, Moscow, 2009) (in Russian)

9. R.Z. Valiev, I.V. Alexandrov, Bulk nanostructured metallic materials, 397 (M: «Akademika», 2007)

10. N. Yu. Dudareva, Russian Aeronautics 51, 321 (2008)

11. M. M. Krishtal, Advanced Materials Research 59, 204 (2009)

12. M. M. Krishtal, Metal Science and Heat Treatment 46, 377 (2004)

13. T. Wei, J. Journal of Alloys and Compounds 389, 169 (2005) 